\title{
Chemical processing of modified lead titanate
}

\author{
A. AHMAD, K. BESSO* , S. CHEHAB, T. A. WHEAT \\ Ceramic Section and * Mineralogy Section, Mineral Processing Laboratories, CANMET, \\ Energy Mines and Resources, 555 Booth St., Ottawa, Ontario, Canada, K1A OG 1 \\ D. NAPIER \\ Chemical Engineering Department, University of Waterloo, Ontario, Canada, N2L 3G1
}

A modified lead titanate composition has been synthesized by two different chemical techniques. The influence of the powder processing methods and the calcination temperatures on the physical characteristics, e.g. surface area and phase compositions of the powders, has been investigated. Powders of the same composition have also been prepared by attrition milling the raw materials. Results of the preliminary investigations indicate that the above physical characteristics are strongly dependent on the powder processing methods and calcination temperatures.

\section{Introduction}

Piezoelectrics are crystalline materials that produce a voltage proportional to an applied pressure. Conversely, an applied electric field results in structural deformation of the piezoelectrics. Such properties are the basis for the wide-ranging applications of these materials, such as record player pick-ups, aerospace accelerometers, high-frequency filters, high-precision motors and generators.

Because of the high anisotropy in the crystal structure, pure lead titanate $\left(\mathrm{PbTiO}_{3}\right)$ cannot be sintered to high densities. Doping with alkali metals, transition metals and rare earths has been shown to produce the desired high-density sintered material $[1-4]$. The large thickness mode electromechanical coupling factor $\left(k_{\mathrm{t}}\right)$ and a small planar mode coupling factor $\left(k_{\mathrm{p}}\right)$ of $\mathrm{PbTiO}_{3}$ make it a particularly promising material for ultrasonic transducers used in non-destructive structural testing. Such transducers generate sound waves of 50 to $100 \mathrm{MHz}$ which can be utilized in the imaging and characterization of micro-cracks and subsurface flaws invisible to optical inspection in various structures [5].

The properties of lead titanate ceramics such as phase composition, sintered density, microstructure, electrical and mechanical properties can be altered by varying the processing and forming parameters. Powder preparation methods, composition, homogeneity, particle size, particle size distribution and surface area can profoundly influence the final product. It is in this regard that doped ceramics present a particularly challenging problem. Uneven dopant distribution, small variations in the amount present or minute amounts of inadvertent contaminants can drastically alter the properties of a ceramic. Hence, there is a need to study and understand the effects of these processing parameters so that the properties of materials can be tailored to meet the demands of a specific application.

Ceramic processing in this area has conventionally involved mechanically mixing and grinding the component powders (in this case $\mathrm{PbO}, \mathrm{TiO}_{2}$ plus the oxides or carbonates of dopants) into a fine homogeneous powder. Another approach to maximizing homogeneity and optimizing particle size involves the use of wet chemical methods, e.g. co-precipitation from inorganic salts [6-8], hydration of organometallic compounds [9-10] or sol-gel processing [11-12] of the ceramics. Such methods should exploit the homogeneity of aqueous (or non-aqueous) solutions, as well as the physical and chemical properties of an intermediate product, to yield calcined powders superior to powders obtained by conventional solidstate methods. By avoiding any kind of mechanical processing (especially grinding), contamination can be minimized, resulting in powders of exceedingly high purity.

The purpose of this study is to synthesize a modified lead titanate based upon the general formula $\left[\mathrm{Pb}_{1-x} \mathrm{Ca}_{x}\right]\left[(\mathrm{Co}, \mathrm{W})_{y} \mathrm{Mn}_{z} \mathrm{Ti}_{1-2 y-z}\right] \mathrm{O}_{3}$, where $x \leqslant 0.35$, $y \leqslant 0.03, z \leqslant 0.01$, by two different chemical routes and also by an attrition-milling method, and to study the influence of the various powder processing techniques and calcination temperatures on the physical characteristics of the ceramic powders.

\section{Materials and methods}

The following procedures were developed to produce the powders used in this study.

\subsection{Attrition milling}

Powders were prepared from high-purity ( $>99.5 \%$ ) commercial raw materials. Initially the raw materials (in the form of oxides or carbonates) were weighed to produce 300 to $400 \mathrm{~g}$ batches and dry mixed in a rotary mixer for $24 \mathrm{~h}$. The mixed powders were then transferred to a 11 attrition-mill container which was filled to about one-half capacity with high-purity zirconia attrition medium (spherical, $3 \mathrm{~mm}$ diameter). Enough 
water was added to cover the surface of the zirconia beads along with $0.55 \%$ (by weight) of the deflocculent Darvan " $\mathrm{C}$ ". The slurry was attrition milled for $4.5 \mathrm{~h}$ and then spray dried using a Buchi model 190 spray drier at an inlet temperature of about $220^{\circ} \mathrm{C}$ and the outlet temperature of around $125^{\circ} \mathrm{C}$. This produced a fine, free-flowing powder.

\subsection{Chemical routes}

Two wet-chemical routes were used. Both methods involved the formation of a solid from a solution and both involved heating this intermediate solid to obtain doped $\mathrm{PbTiO}_{3}$ powders. The nature and processing of these solutions were different.

\subsubsection{Method A}

$\mathrm{PbCO}_{3}$ was dissolved in a minimum amount of aqueous acetic acid and calcium, manganese and cobalt acetates were added to give a clear pink solution. Tetra$n$-butoxy titanium $\left(\mathrm{TNBT}=\mathrm{Ti}\left(\mathrm{O}\left(\mathrm{CH}_{2}\right)_{3} \mathrm{CH}_{3}\right)_{4}\right)$ was added dropwise to $80 \%$ acetic acid (about $1 \mathrm{ml}$ acetic acid/ml TNBT) giving a clear gold-yellow solution that was $1.35 \mathrm{M}$ titanium. The solution was added in one lot to the pink solution of acetates, forming a clear orange solution.

Rotary evaporation (at about $35^{\circ} \mathrm{C}$ ) was used to reduce the volume of the orange solution to less than one-third of its initial volume. The evaporated residue was a clear red viscous liquid (density 1.4 to $1.5 \mathrm{~g} \mathrm{ml}^{-1}$ ).

Two variations of this method were used to recover a solid from the red, viscous liquid.

\subsubsection{Rotary evaporation/oven drying. The water} content of the liquid was estimated by removing a small amount for drying in an oven at $120^{\circ} \mathrm{C}$. All the weight loss was attributed to water and a nine-fold volume excess of isopropanol was added, causing a thick, pink slurry to form. Water was removed as an azeotrope, leaving a wet-looking, pink material that smelled of acetic acid. There appeared to be some spots where a clear gel had formed. The pink material was oven dried at $120^{\circ} \mathrm{C}$ overnight and formed a purple opaque glass-like material. Chips of this material were hand ground into a powder. The powder was oven dried at $150^{\circ} \mathrm{C}$ and continued to lose weight after $12 \mathrm{~h}$ at this temperature, suggesting slow thermal decomposition.

2.2.1.2. Splat drying/oven drying. The viscous liquid was added dropwise to a seven-fold volume excess of vigorously stirred isopropanol, forming a precipitate. A thick, purplish slurry had formed by the time addition was complete and this slurry was splat dried on a Pyrex dish. The splat-dried material was oven dried at $120^{\circ} \mathrm{C}$ overnight to remove acetic acid. Soft greyish flakes of the material were recovered and hand ground into a free-flowing, off-white powder.

\subsubsection{Method B}

A solution of lead/calcium/manganese and cobalt acetates in the same mole ratio as Method $\mathrm{A}$ was made up. The solution was $1.05 \mathrm{M}$ with respect to lead.
TNBT was dissolved in excess oxalic acid, forming a yellow solution that was $0.23 \mathrm{M}$ in titanium.

The acetate solution was added dropwise to the titanium solution while stirring vigorously. When addition was complete, a pinkish precipitate had formed. Aqueous ammonia (concentrated) was added, raising the $\mathrm{pH}$ from 1.5 to 8.5 . A gelatinous, white material precipitated out upon addition of ammonia. The slurry was filtered in a Buchner funnel through a Whatman type-42 filter paper, giving 2.61 clear pink filtrate. The dense white residue on the filter paper was oven dried overnight at $115^{\circ} \mathrm{C}$.

The oven-dried material was light pink and hard, and was hand ground into a light pink powder.

\subsection{Calcination}

Powders were calcined in small batches $(<10 \mathrm{~g})$ in alumina crucibles at temperatures ranging from 100 to $800^{\circ} \mathrm{C}$. The crucibles were covered using a loosely fitted platinum foil and heated in a temperaturecontrolled furnace at $8^{\circ} \mathrm{C} \mathrm{min}^{-1}$ to the desired temperature, held there for a period of $2 \mathrm{~h}$ and allowed to cool down to room temperature by turning off the furnace.

\subsection{X-ray diffraction and surface area studies}

X-ray diffraction patterns were obtained using a Rigaku automated powder diffractometer with $\mathrm{Cu} K \alpha$ radiation and a graphite monochromator. The lattice parameters were determined with the aid of software developed in-house to calculate the $a$ and $c$ parameters and the cell volumes of the tetragonal unit cell upon input of the angles of diffraction and their corresponding $h k l$ indices.

The surface-area measurements were made by the BET method using a Quantasorb model QS-10 surface area measurement instrument obtained from Quantachrome Powder Technology Corporation, New York, USA.

\section{Results and discussion}

\subsection{Surface area measurements}

The surface area of the powders in this study showed dependence on three different processing parameters including the powder synthesis method, the calcination temperature and the drying method. The surface area measurements are shown in Table I. An analysis of the data indicates that at low temperature $\left(150^{\circ} \mathrm{C}\right)$, compared to the chemically derived material, powders produced by the attrition milling/spray drying process exhibit the highest surface area. This could be due to the higher rate of solvent (water) evaporation during spray drying of the fine attrition-milled slurry under high temperature $\left(220^{\circ} \mathrm{C}\right)$ and highvacuum conditions. This generally promotes the formation of the soft agglomerated powders having reasonably high surface area. On the other hand, chemically derived powders contained harder agglomerates due presumably to the increased degree of cross-linking that occurs as the extensively hydrated surface of the precipitates is dried. This does not occur in the attrition-milled materials as the degree of hydration is considerably lower. 
TABLE I Data from surface area measurements $\left(\mathrm{m}^{2} \mathrm{~g}^{-1}\right)$

\begin{tabular}{|c|c|c|c|c|}
\hline \multirow{4}{*}{$\begin{array}{l}\text { Temperature } \\
\left({ }^{\circ} \mathrm{C}\right)\end{array}$} & \multicolumn{4}{|c|}{ Powder preparation method } \\
\hline & \multicolumn{2}{|c|}{ Method A: acetate-gel } & \multirow{2}{*}{$\begin{array}{l}\text { Method B: } \\
\text { co-precipitation } \\
\text { oxalate/hydroxide }\end{array}$} & \multirow{2}{*}{$\begin{array}{l}\text { Method C: } \\
\text { attrition milling } \\
\text { and spray drying }\end{array}$} \\
\hline & Splat dried & Rotary evaporation & & \\
\hline & & & Rotary evaporation & Spray dried \\
\hline 150 & 0.98 & 1.38 & 1.68 & 7.60 \\
\hline 400 & 66.50 & - & 27.00 & 5.13 \\
\hline 500 & 34.20 & 38.70 & 13.80 & 3.56 \\
\hline 600 & 16.60 & 21.20 & 6.20 & 2.80 \\
\hline 700 & 7.75 & 10.10 & 3.50 & - \\
\hline 800 & 3.34 & 4.32 & 2.36 & 0.85 \\
\hline
\end{tabular}

In the case of the chemically derived materials from Method A (acetate-gel route), powders produced by splat drying exhibited a relatively lower surface area compared to the rotary evaporation method. This may be due to the greater thermal shock experienced by the particles while being poured on a hot (120 to $150^{\circ} \mathrm{C}$ ) Pyrex plate used for splat drying. This may result in the formation of the harder agglomerates causing reduction in the surface area of the powders. The rotary evaporation in this study was conducted at $35^{\circ} \mathrm{C}$ under low vacuum conditions, producing relatively softer agglomerates and consequently higher surface area powders.

As the calcination temperature increased, the attrition milled/spray dried powders exhibited a decrease in surface area due to high-temperature densification of the particles. In contrast, the chemically derived powders at first showed a large increase in surface area due presumably to the decomposition of the organic materials, resulting in the formation of internal microcracks. The surface areas of the splat-dried powders from Method A were 66.5 and $34.2 \mathrm{~m}^{2} \mathrm{~g}^{-1}$ when calcined at 400 and $500^{\circ} \mathrm{C}$, respectively. Assuming spherical particle geometry, this corresponds to a particle size of 12.6 and $24.6 \mathrm{~nm}$, respectively. The surface area, however, decreased upon further increase in temperature. At $800^{\circ} \mathrm{C}$ the surface area of the chemically derived powders still remains three to five times higher than that of the conventional attrition-milled material. The data in Table I suggest that chemically derived materials can furnish powders having a wide range of particle sizes and surface areas through appropriate control of the calcination temperature. The high surface area is attractive for producing thick film formulations using this material. The high surface area may also be useful for sensor applications that generally demand high catalytic activity from the ceramics for faster response time. However, for bulk applications (e.g. discs, tubes, etc.) the high surface area of the material may produce adverse effects. This is due to difficulties normally encountered in obtaining high green-density bodies from high surface-area powders during the forming process, which ultimately leads to poor sintered density of the bulk material. The high surface-area fine particles also demand special consideration in powder handling, especially in an industrial environment.

\subsection{X-ray diffraction data (XRD)}

The XRD data in this study (Figs 1 to 3 ) exhibit strong dependence on the powder synthesis method and calcination temperatures. XRD patterns for powders produced from Method A (acetate-gel route) were amorphous up to $360^{\circ} \mathrm{C}$ calcination temperatures (Fig. 1). At $500^{\circ} \mathrm{C}$, the $\mathrm{PbTiO}_{3}$ perovskite phase was clearly observed along with trace amounts of orthorhombic lead oxide $\mathrm{PbO}(\mathrm{o})$. At $600^{\circ} \mathrm{C}$, the $\mathrm{PbTiO}_{3}$ phase $\mathrm{PbO}(\mathrm{t})$ was well resolved and trace amounts of orthorhombic $\mathrm{PbO}$ were still noticed. At $700^{\circ} \mathrm{C}$, the orthorhombic $\mathrm{PbO}$ phase disappeared and wellresolved lead titanate, along with trace amounts of tetragonal $\mathrm{PbO}$ phase, were observed. Further increase in calcination temperature to $800^{\circ} \mathrm{C}$ resulted in the formation of pure perovskite lead titanate phase.
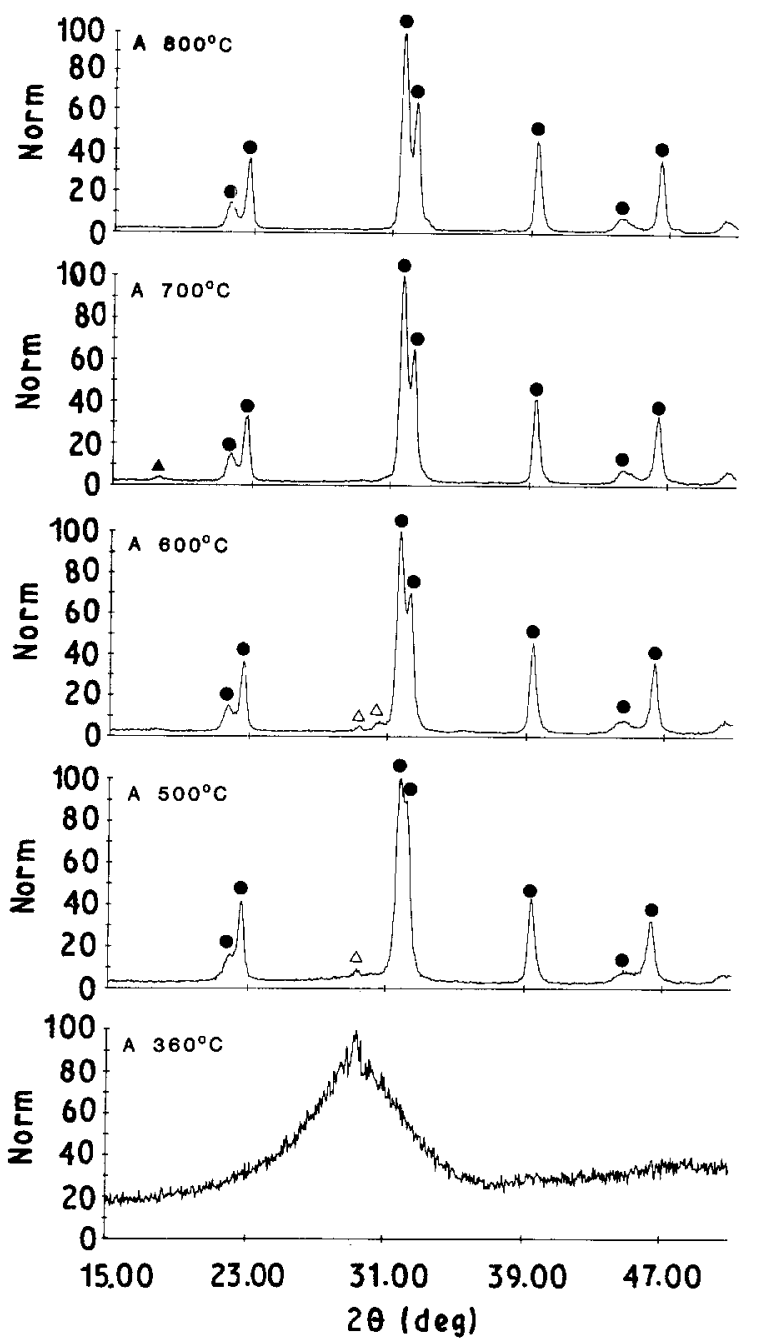

Figure 1 Temperature dependence of the XRD patterns for powders prepared by Method A (acetate-gel route). (•) $\mathrm{PbTiO}_{3},(\boldsymbol{\Delta}) \mathrm{PbO}(\mathrm{t})$, ( $\triangle) \mathrm{PbO}(0)$. 


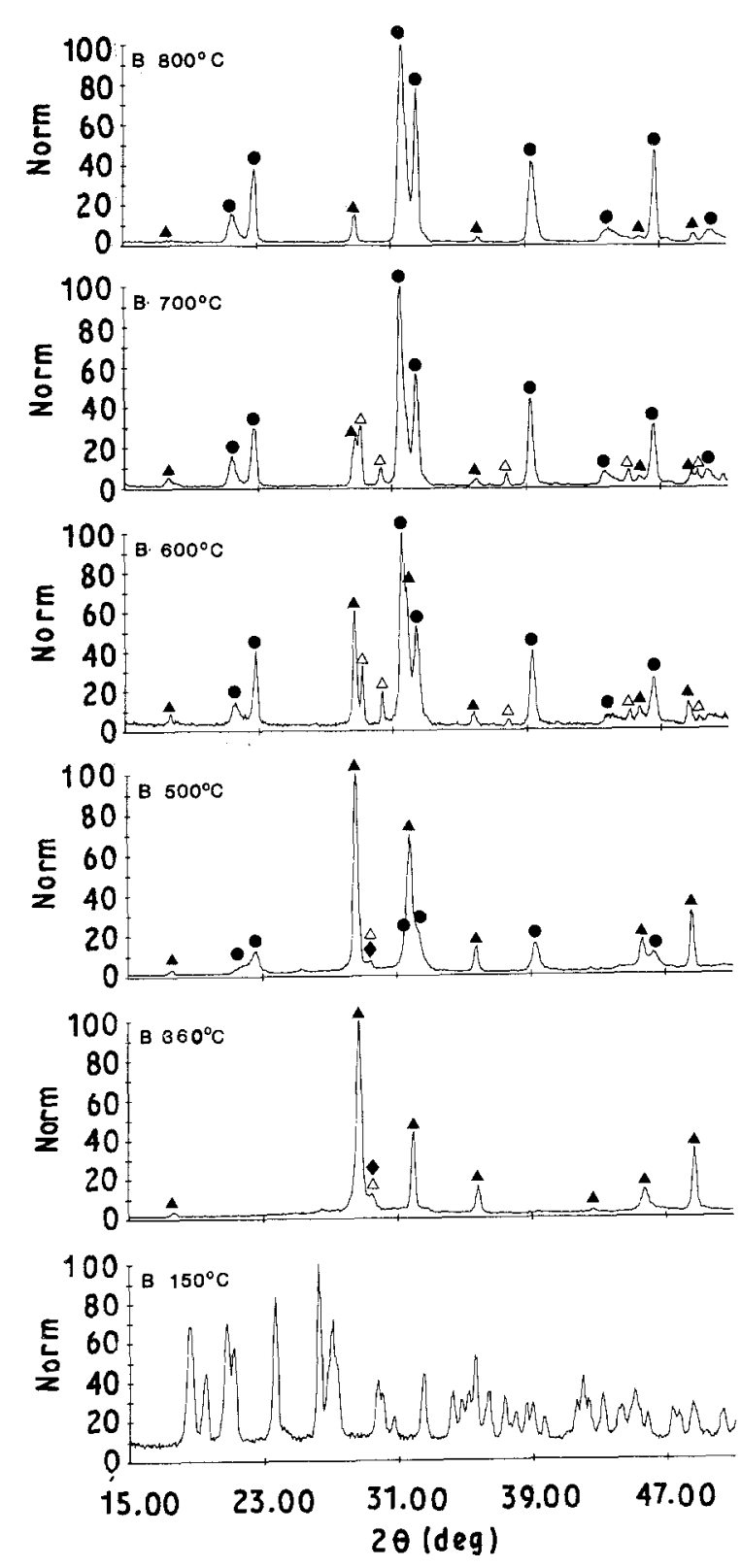

Figure 2 Temperature dependence of the XRD patterns for powders prepared by Method B (co-precipitation). (•) $\mathrm{PbTiO}_{3}$, (४) $\mathrm{PbO}(\mathrm{t})$, (৬) $\mathrm{CaCO}_{3},(\Delta) \mathrm{PbO}(\mathrm{o})$.

Unlike Method A, as-dried $\left(150^{\circ} \mathrm{C}\right)$ powders from Method B (co-precipitation route) showed a crystalline structure indicating that the co-precipitation reaction does not influence the crystallinity of reaction mixture. Lead oxalate was the major phase at this temperature with the possibility of titanium oxalate lead hydrate as a minor phase. At $360^{\circ} \mathrm{C}$, the decomposition of the oxalate resulted in the formation of tetragonal lead oxide as a major phase. Trace amounts of orthorhombic $\mathrm{PbO}$ and/or $\mathrm{CaCO}_{3}$ phases were also detected. At $500^{\circ} \mathrm{C}$, a small amount of lead titanate along with the above phases appeared. Raising the temperature to $600^{\circ} \mathrm{C}$ resulted in a decrease in peak intensities for tetragonal $\mathrm{PbO}$, an increase in peak intensities for lead titanate perovskite phase, and the orthorhombic $\mathrm{PbO}$ phase was now clearly observed. Further increase in temperature resulted in a decrease in peak intensities for both $\mathrm{PbO}$ phases. At $800^{\circ} \mathrm{C}$ the orthorhombic $\mathrm{PbO}$ phase disappeared and wellresolved perovskite lead titanate phase along with
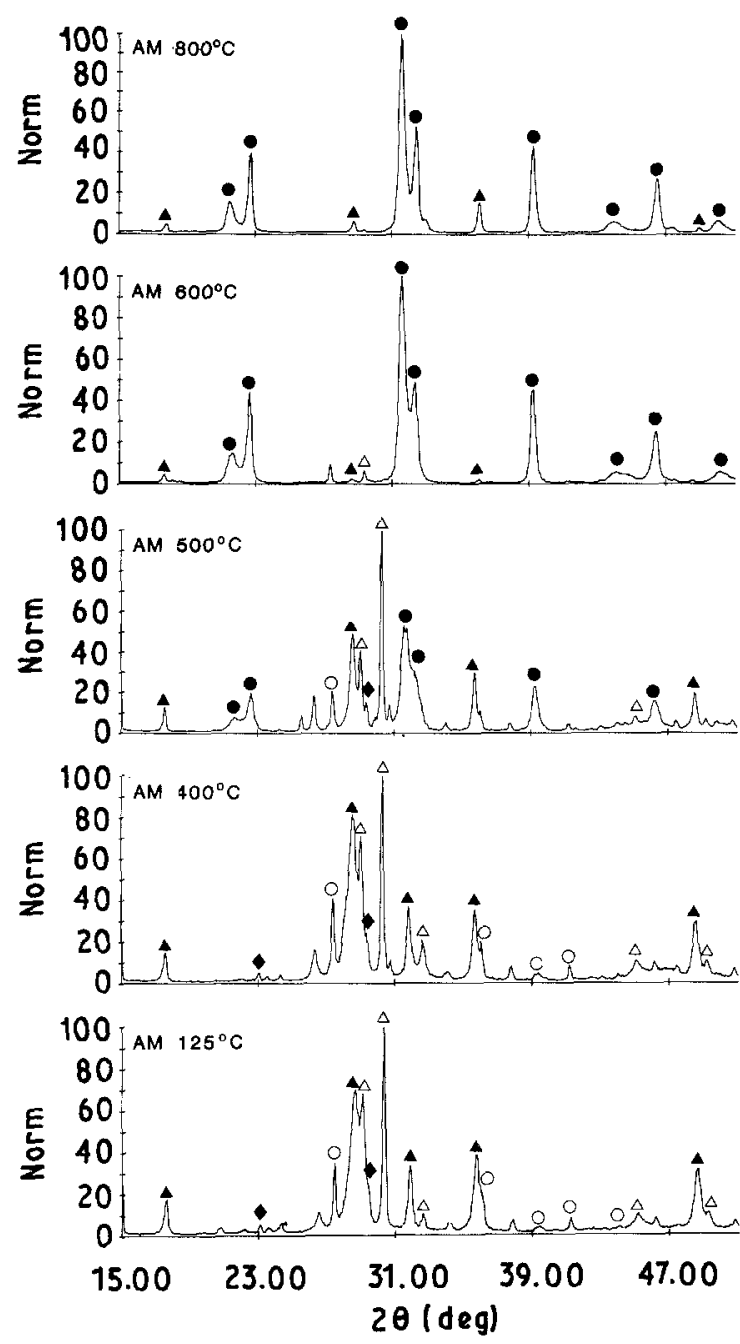

Figure 3 Temperature dependence of the XRD patterns for powders prepared by attrition milling/spray drying method. (•) $\mathrm{PbTiO}_{3}$, (৯) $\mathrm{PbO}(\mathrm{t}),(\diamond) \mathrm{CaCO}_{3},(\Delta) \mathrm{PbO}(\mathrm{o}),(\mathrm{o}) \mathrm{TiO}_{2}$.

trace amounts of tetragonal lead oxide $(\mathrm{PbO}(\mathrm{t}))$, were clearly noticed.

The XRD patterns for the attrition milled/spray dried powders were relatively more complex. Up to a temperature of $400^{\circ} \mathrm{C}$, the XRD spectra Fig. 3 mainly consisted of orthorhombic and tetragonal lead oxides, rutile $\left(\mathrm{TiO}_{2}\right)$ and calcium carbonate. At low temperatures $\left(125\right.$ to $\left.400^{\circ} \mathrm{C}\right)$ some of the smaller peaks could not be identified. A computerized phase search using these peaks did not lead to any definite conclusions. At $500^{\circ} \mathrm{C}$ tetragonal lead titanate phase appeared along with the other phases previously observed. At $600^{\circ} \mathrm{C}$ the lead titanate phase was clearly resolved, trace amounts of tetragonal/orthorhombic

TABLE II Lattice parameters from XRD data

\begin{tabular}{lllll}
\hline $\begin{array}{l}\text { Sample ID } \\
\text { temperature }\left({ }^{\circ} \mathrm{C}\right)\end{array}$ & $a(\mathrm{~nm})$ & $c(\mathrm{~nm})$ & $c / a$ & Volume $\left(\mathrm{nm}^{3}\right)$ \\
\hline A 600 & 0.39082 & 0.40585 & 1.038 & 0.061992 \\
B 600 & 0.39002 & 0.41304 & 1.059 & 0.062831 \\
AM 600 & 0.39102 & 0.41065 & 1.050 & 0.062789 \\
A 800 & 0.38974 & 0.40897 & 1.049 & 0.061220 \\
B 800 & 0.38861 & 0.41316 & 1.063 & 0.062396 \\
AM 800 & 0.38953 & 0.40903 & 1.050 & 0.062065 \\
\hline
\end{tabular}

A, Method A: (acetate-gel).

B, co-precipitation Method B: (oxalate/hydroxide).

AM, attrition-milled and spray-dried. 
$\mathrm{PbO}$ and rutile $\left(\mathrm{TiO}_{2}\right)$ phases were also present. At $800^{\circ} \mathrm{C}$ the well-resolved lead titanate phase and a small amount of tetragonal $\mathrm{PbO}$ phase were clearly observed.

The tetragonal unit cell parameters including $a$ and $c$ axis, $c / a$ ratio and the unit cell volume for the lead titanate phase were calculated from the X-ray data for powders calcined at 600 and $800^{\circ} \mathrm{C}$. The cell parameters were calculated from X-ray data using a least squares cell refinement program. For each sample, 13 XRD peaks having the same $h k l$ indices were chosen for data calculation in the $2 \theta$ range from $20^{\circ}$ to $80^{\circ}$. The data are presented in Table II. As indicated in Table II, the values for the $a$-axis exhibit a slight decrease and the $c$ axis show a slight increase with an increase in the calcination temperature from 600 to $800^{\circ} \mathrm{C}$. Irrespective of the calcination temperature, the powders produced from Method B (coprecipitation route) exhibited the highest tetragonality (c/a ratio). Both the cell volume and the $c / a$ ratio had lower values for powders prepared by Method A (acetate-gel route).

Powders prepared by Method A and calcined at $600^{\circ} \mathrm{C}$ had the lowest $c / a$ value $(1.038)$ whereas those produced by Method $\mathrm{B}$ and calcined at $800^{\circ} \mathrm{C}$ displayed the highest $c / a$ ratio (1.063). The lower tetragonality is desirable as it reduces the crystal strain during sintering of the lead titanate. Because of the large crystal anisotropy $(c / a=1.065)$, undoped lead titanate develops micro/macrocracks due to the differential thermal strain along the $a$ - and $c$-axes when cooled through the Curie point during the sintering process. The above results suggest that the powders produced using Method A may provide better sintered density material.

\section{Conclusions}

The results suggest that both the surface area and the phase compositions of the lead titanate powders produced in this work are strongly influenced by the powder preparation method and the calcination temperatures. The method of drying also affects the surface area of the powders. Powders prepared using Method A and dried by the rotary evaporation method displayed the highest surface area. The surface area of the chemically derived powders calcined at $400^{\circ} \mathrm{C}$ and above were substantially higher than the surface area of powders produced by a conventional attrition milling process. The high surface area may be of particular importance for thick films or sensor applications that exploit high-temperature reactivity and higher catalytic activity characteristics of the ceramic powders.

The XRD data indicate that the powders synthesized using Method A provide pure perovskite lead titanate phase at $800^{\circ} \mathrm{C}$. Both co-precipitated and attrition-milled powders contained other phases up to this calcination temperature. Even at lower temperatures, the amount of minor phases in powders A is significantly smaller than in the powders from the other routes. This suggests that Method A provides powders having higher reactivity at relatively lower temperatures. The tetragonality of the unit cells $(c / a)$ and unit cell volumes by Method A were also of the lowest value. This is a desirable feature as it improves the sinterability of lead titanate. The influence of the above powder processing techniques on the sintering, microstructure, dielectric and piezoelectric properties of this material is being investigated and will be the subject of another publication.

\section{Acknowledgements}

The authors acknowledge the technical assistance of A. G. McDonald and P. Carrière, Mineral Sciences Laboratories (CANMET) for sample preparations and XRD data. The authors also thank Drs A. K. Kuriakose and D. H. H. Quon, Ceramic Section, for helpful discussions, and Dr J. T. Szymanski, Mineralogy Section (CANMET), for assistance in evaluating lattice parameters from XRD data and for many enlightening discussions.

\section{References}

1. I. UDEA, Jpn J. Appl. Phys. 11 (1972) 450.

2. L. EYARUD, P. EYARUD, F. GONNARD and M. TROCCAZ, Ferroelectrics 34 (1981) 133.

3. P. DURAN, F. CAPEL, J. R. JUARDO and C. MOURE, in "High Tech Ceramics", edited by P. Vincenzi (Elsevier, Amsterdam, 1987) 1661.

4. A. AHMAD, T. A. WHEAT, A. K. KURIAKOSE, D. H. H. QUON and R. BERRY, MSL Division Report (1988), No. 88-19(OP), CANMET, EMR, Canada.

5. M. G. SILK, "Ultrasonic Transducers for Nondestructive Testing" (Adam Hilger, Bristol, 1984)

6. W. K. LIN, M. S. JOU and Y. H. CHANG, Ceram. Int. 14 (1988) 223.

7. J. R. THOMSON, Ceram. Bull. 53 (1974) 421.

8. M. MURATA, K. WAKINO, K. TANAKA and Y. HAMAKAWA, Res, Bull. 11 (1976) 323.

9. G. H. HAERTLING and C. E. LAND, Ferroelectrics 3 (1972) 269.

10. L. M. BROWN and K. B. MAZDIYAZNI, J. Amer. Ceram. Soc. 55 (1972) 541.

11. S. R. GURKOVICH and J. B. BLUM, J. Mater. Sci. 20 (1985) 4479 .

12. K. D. BUDD, S. K. DEY and D. A. PAYNE, in British Ceramic Proceedings No. 36, "Electrical Ceramics", edited by B. C. H. Steele, Stoke-On-Trent, UK, 17-18 December, (1985) pp. 107-122.

Received 29 June

and accepted 1 December 1989 